\title{
Prevalence and types of pterygium in a tertiary hospital in Puducherry - A descriptive cross sectional study
}

\author{
T. Vijhaya Priya ${ }^{1, *}$, Rathinakumar ${ }^{2}$, P. Amudha ${ }^{3}$, S. Venipriya ${ }^{4}$, K. Renuga Devi ${ }^{5}$ \\ ${ }^{1}$ Associate Professor, ${ }^{3}$ Assistant Professor, ${ }^{4,5}$ Senior Resident, Dept. of Ophthalmology, ${ }^{1,3-5}$ Indira Gandhi Medical College and \\ Research Institute (Govt), Puducherry, ${ }^{2}$ Professor, Dept. of Ophthalmology Sri Lakshmi Narayana Institute of Medical Sciences, \\ Puducherry, India
}

*Corresponding Author:

Email: tvijhayapriya@yahoo.com

\begin{abstract}
Introduction: A pterygium is a triangular fibrovascular subepithelial growth of bulbar conjunctival tissue that has invaded the superficial cornea, causing visual impairment. It is a degenerative condition.

Objectives: To study the prevalence and types of pterygium in patients in a tertiary hospital in Puducherry

Materials and Methods: A descriptive cross sectional study was done for a period of 6 months, in the out patient department of ophthalmology. Out of the 6028 patients who had registered, the clinical records of 345 patients with pterygium were retrieved and analysed using MS office Excel sheet

Results: The results depict that females (59\%) were more affected than the males (41\%) and nasal pterygium was more common than the temporal pterygium. It was also found that unilateral pterygium (81\%) is more common than bilateral pterygium (15\%) and progressive pterygium (67\%) is more common than atrophic or recurrent types. Analysis also revealed that type I pterygium $(51 \%)$ is more common

Conclusion: The prevalence of pterygium increased with increasing age and long term exposure to sunlight. It can be decreased by using protective measures
\end{abstract}

Keywords: Nasal pterygium, Pterygium, Prevalence, Progressive pterygium, Types.

\section{Introduction}

Pterygium is triangular fibrovascular subepithelial growth of bulbar conjunctival tissue which arises due to chronic exposure to UV B rays, dust, dryness chronic irritation and abnormal blinking patterns. It is organised into head, neck and body. The pterygium causes anatomical and physiological changes in the tear film, corneal distortion can lead to induced astigmatism, visual impairment occurs due to interference with visual axis, it can cause double vision and it also causes obvious cosmetic problems. Progressive pterygium is thick, fleshy and vascularised whereas an atrophic pterygium is less vascular and thin. Type I pterygium shows $<2 \mathrm{~mm}$ encroachment into the cornea. Type II between 2 to $4 \mathrm{~mm}$ and type III $->4 \mathrm{~mm}$ encroachment on to the cornea. ${ }^{1,2}$ Use of protective goggles can retard the progression of pterygium. Treatment for pterygium has been improved in recent years. The recurrence rate after pterygium excision with limbal conjunctival autograft was lower than that of bare sclera. ${ }^{3}$ There is dearth of information regarding the prevalence and types of pterygium in the coastal town of Puducherry. This study was performed to provide informative resources on prevalence and types of pterygium. This helps us to create awareness about pterygium in the community.

\section{Materials and Methods}

A facility - based descriptive cross sectional study was done in the ophthalmology out patient department between January 2017 and June 2017. Out of a total of 6028 patients with various ocular disorders who attended the OPD, $345(5.7 \%)$ patients were diagnosed to have pterygium. The clinical case records of all the 345 patients with pterygium (5.7\%) were retrieved and analysed for demographic data, laterality, site and type.

Inclusion Criteria: Patients in the age group 31 to 80 years with pterygium were included in the study.

Exclusion Criteria: Patients with pseudo pterygium were excluded.

Clearance was obtained from ethics review committee. All patients fulfilling the above criteria were included in the study. The data were tabulated in MS office Excel sheet and analysed.

\section{Results}

Out of the 345 patients, $41 \%$ were males and $59 \%$ were females. It shows that females were more affected than males. 32 (18 males and 14 females) patients were in the age group of 31-40 years, 120 (46 males and 74 females) patients in the age group 41-50 years, 143 patients (55 males and 88 females) in the age group of 51-60 years, 31 (15males and 16 females) patients in the age group 61-70 years and 19 (8 males and 11 females) patients in the age group 71 -80 years. 


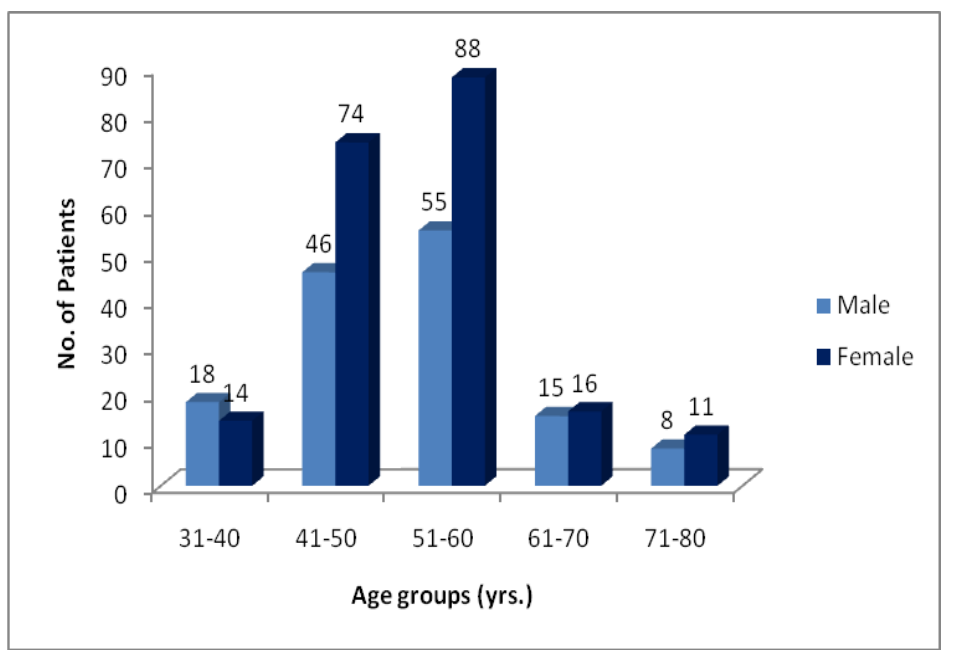

Fig. 1:

High prevalence of pterygium was seen in farmers (153 patients), followed by manual labourers ( 81 patients) and street vendors (78 patients) and lesser prevalence was seen in home makers (33 patients)

\section{Fig. 2:}

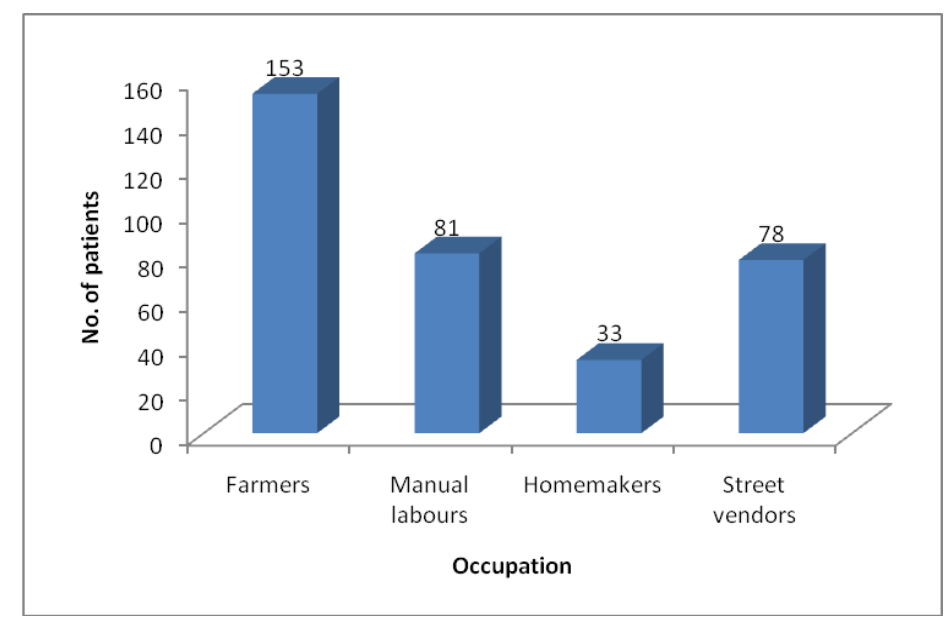

Most of the cases $80 \%$ (276 patients) had unilateral pterygium and $20 \%$ (69 patients) had bilateral pterygium. As there were 69 patients with bilateral pterygium, the total eyes having pterygium were 414 . Amongst these cases, majority were nasal pterygium (81\%), $15 \%$ of the pterygium were temporal and $4 \%$ pterygium were double pterygium.
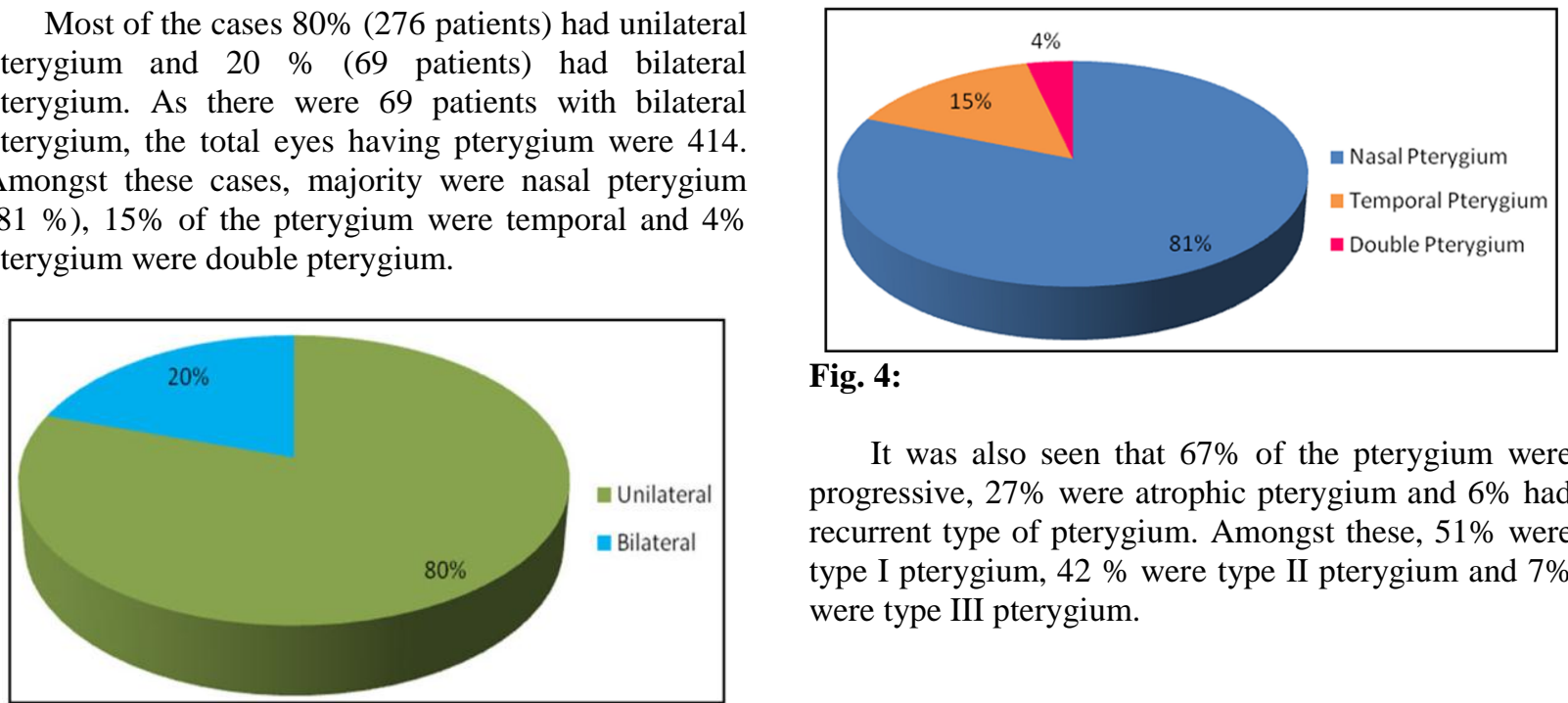

Fig. 4:

It was also seen that $67 \%$ of the pterygium were progressive, $27 \%$ were atrophic pterygium and $6 \%$ had recurrent type of pterygium. Amongst these, $51 \%$ were type I pterygium, $42 \%$ were type II pterygium and $7 \%$ were type III pterygium.

Fig. 3: 


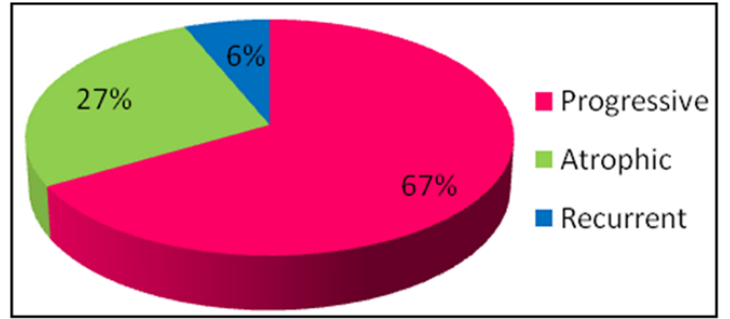

Fig. 5:

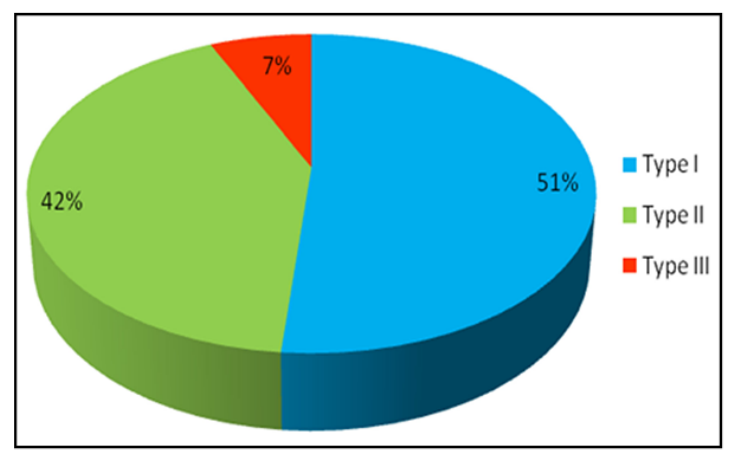

Fig. 6:

\section{Discussion}

Our study showed that the prevalence of pterygium was more in females than males. A study by Lu et al reported that women were at higher risk than men. ${ }^{4}$ Some studies found that men have higher prevalence than women ${ }^{5-7}$ where as some studies show that there is no significant difference in the prevalence between men and women. ${ }^{8,9}$ This variability could be due to the difference in risk factors in different areas

In our study, prevalence of pterygium increased with age, but was found to be almost the same in patients more than 60 years of age. Most of the studies also show that the prevalence of pterygium increased with age. ${ }^{10,11}$

Highest prevalence was seen in farmers, and manual labourers and street vendors as they spent most of their day time outdoors and increased exposure to UV rays from sun, dust and dryness increased the prevalence of pterygium. Similar observation were done by Chavan WM et al ${ }^{12}$ and Maharjan IM et al. ${ }^{13}$ Their studies reveal that $(82 \%)$ patients who were farmers and $64.66 \%$ of the outdoor workers had pterygium respectively

$80 \%$ of our cases were unilateral and the most common site of occurrence was nasal $(81 \%)$. This was similar to the findings of Krishnaram ${ }^{14}$ who found that the prevalence of nasal pterygium was $99 \%$. A study by Chavan WM et $\mathrm{al}^{10}$ found that $100 \%$ of pterygium were nasal and Rohatgi $\mathrm{S}^{15}$ found that $92 \%$ cases of pterygium belong to nasal side, while only $4 \%$ were temporal side. The higher incidence of pterygium on nasal side was due to flow of tears towards the punctum and the sand and dust particle moved towards nasal side. It is also thought that the predominance of nasal pterygium is due to reflection of ultraviolet light from the nose to nasal conjunctiva. Durkin SR et al. ${ }^{16}$ in Meiktila eye study in Australia showed that $8 \%$ of cases had bilateral pterygium where as our study showed that $20 \%$ of the pterygium were bilateral.

In our stud $67 \%$ of the pterygium was progressive, $27 \%$ were atrophic pterygium and $6 \%$ were recurrent type. It was also observed that $51 \%$ were type I pterygium, $42 \%$ were type II pterygium and $7 \%$ were type III pterygium. In a study by Shrestha $\mathrm{P}^{11}$ et al Grade I lesions were more commonly seen while grade II lesions were observed more in patients with predominantly outdoor occupation

\section{Conclusion}

It can be concluded that pterygium is a degenerative condition which is a significant visual problem. Pterygium is more common in patients who do outdoor work which can be decreased by wearing photo protective goggles while working. ${ }^{17}$ These types of descriptive analytical studies are important from various regions of our country so as to improve the health care services with speciality care in all government/private hospitals so as to prevent visual impairment

\section{References}

1. Kanski, Jack J, Brad Bowling, Ken K. Nischal, and Andrew Pearson. Clinical Ophthalmology: A Systematic Approach. Seventh ed. Edinburgh:

Elsevier/Saunders;2011.163p.

2. Bhandari V, Roa CL, Ganesh S, Brar S. "Visual outcome and efficacy of conjunctival autograft, harvested from the body of pterygium in pterygium excision" Clinical Ophthalmology, Dec 2015 Vol9;2285-90.

3. K. Zheng, J. Cai, V. Jhanji, and H. Chen, "Comparison of pterygium recurrence rates after limbal conjunctival autograft transplantation and other techniques: metaanalysis," Cornea, vol. 31, no. 12, pp. 1422-1427, 2012.

4. Lu P, Chen X, Kang Y, et al. Pterygium in Tibetans: a population based study in China. Clin Experiment Ophthalmol 2007;35:828-33.

5. H. Shiroma, A. Higa, S. Sawaguchi et al., "Prevalence and risk factors of pterygium in a South western island of Japan: the Kumejima Study," American Journal of Ophthalmology, vol. 148, no. 5, pp. 766.e1-771.e1, 2009.

6. T. Y. Wong, P. J. Foster, C. J. Johnson, S. K. Seah, and D. T.Tan, "The prevalence and risk factors for pterygium in an adult Chinese population in Singapore: the Tanjong Pagar survey," American Journal of Ophthalmology, vol. 131, no. 2, pp. 176-183, 2001.

7. C. A. McCarty, C. L. Fu, and H. R. Taylor, "Epidemiology of pterygiumin Victoria, Australia," British Journal of Ophthalmology, vol. 84, no. 3, pp. 289-292, 2000.

8. S.Marmamula, R. C.Khanna, and G.N. Rao, "Populationbased assessment of prevalence and risk factors for pterygium in the South Indian state of Andhra Pradesh: the Andhra Pradesh Eye Disease Study," Investigative Ophthalmology and Visual Science, vol. 54, no. 8, pp. 5359-5366, 2013.

9. W Jiao, C Zhou, T Wang, S Yang, H Bi, L Liu Prevalence and Risk Factors for Pterygium in Rural Older Adultsin Shandong Province of China: A Cross-Sectional 
Study, BioMed Research International Volume 2014 (2014), Article ID 658648, 8 pages.

10. Nangia V, Jonas JB, Nair D, Saini N, Nangia P, PandaJonas S (2013) Prevalence and Associated Factors for Pterygium in Rural Agrarian Central India. The Central India Eye and Medical Study. PLoS ONE 8(12):e82439.

11. Shrestha P, Kaiti R. A Hospital Based Study of Pterygium in Tertiary Care Hospital of Nepal. Kathmandu Univ Med J 2016;55(3):192-7.

12. Chavan WM, Kamble MG, Giri PA. Study of prevalence and socio-demographic determinants of pterygium patients attending at a tertiary care teaching hospital of Western Maharashtra, India. Int J Res Med Sci 2015;3:846-848.

13. Maharjan IM, Shreshth E, Gurung B, Kamacharya S. Prevalence of and associated risk factors for pterygium in the high altitude communities of upper Mustang, Nepal. Nepal J Ophthalmol. 2014;6(11):65-70.

14. K Krishnaram. Prevalence and pattern of pterygium. The Internet Journal of Ophthalmology and visual science 2013;10(1).

15. Rohatgi S. Pterygium: an epidemiological study in India. Int J Healthcare Biomed Res. 2013;1(4):297-301.

16. Durkin SR, Abhary S, Newland HS, Selva D, Aung T, Casson RJ. The prevalence, severity and risk factors for pterygium in central Myanmar: the Meiktila eye study. $\mathrm{Br}$ J Ophthalol. 2008;92:25-9.

17. Luthera R, Leske MC, et al. Frequency and risk factors for pterygium in the Barbados Eye Study. Arch Ophthalmology 2001;119:1827-32. 